\title{
Proton dynamics in cancer
}

\author{
Veronica Huber1', Angelo De Milito2,9, Salvador Harguindey³, Stephan J Reshkin44, Miriam L Wahl5, Cyril Rauch6, \\ Antonio Chiesi², Jacques Pouysségur7, Robert A Gatenby8, Licia Rivoltini and Stefano Fais*2
}

\begin{abstract}
Cancer remains a leading cause of death in the world today. Despite decades of research to identify novel therapeutic approaches, durable regressions of metastatic disease are still scanty and survival benefits often negligible. While the current strategy is mostly converging on target-therapies aimed at selectively affecting altered molecular pathways in tumor cells, evidences are in parallel pointing to cell metabolism as a potential Achilles' heel of cancer, to be disrupted for achieving therapeutic benefit. Critical differences in the metabolism of tumor versus normal cells, which include abnormal glycolysis, high lactic acid production, protons accumulation and reversed intra-extracellular pH gradients, make tumor site a hostile microenvironment where only cancer cells can proliferate and survive. Inhibiting these pathways by blocking proton pumps and transporters may deprive cancer cells of a key mechanism of detoxification and thus represent a novel strategy for a pleiotropic and multifaceted suppression of cancer cell growth.

Research groups scattered all over the world have recently started to investigate various aspects of proton dynamics in cancer cells with quite encouraging preliminary results. The intent of unifying investigators involved in this research line led to the formation of the "International Society for Proton Dynamics in Cancer" (ISPDC) in January 2010. This is the manifesto of the newly formed society where both basic and clinical investigators are called to foster translational research and stimulate interdisciplinary collaboration for the development of more specific and less toxic therapeutic strategies based on proton dynamics in tumor cell biology.
\end{abstract}

Cancer remains a leading cause of death in the world today. Despite decades of research to identify novel therapeutic approaches, durable regressions remain rare in patients with advanced disease, and survival benefits from new therapies are often negligible. Early diagnosis and treatment, rather than successful therapeutic intervention late in the disease process, are mostly responsible for the decreased mortality observed in some types of cancer (WHO).

The war against cancer has been heavily influenced by the principle of Paul Ehrlich's 'magic bullet', an idea originally introduced more than 100 years ago, and validated by the discovery of antibiotics 50 years later. Clinical cancer therapy implicitly assumes that similar magic bullets for cancer can be found with sufficient diligence. However, all attempts to find new drugs that selectively target and kill tumor cells have not been successful [1] and today we are still waiting for the magic bullet directed against most malignant tumors. As a result, alternative

\footnotetext{
* Correspondence: stefano.fais@iss.it
}

2 Department of Therapeutic Research and Medicines Evaluation, Unit of Antitumor Drugs, Istituto Superiore di Sanità, Rome, Italy

Full list of author information is available at the end of the article therapeutic approaches aimed at controlling rather than curing this disease are increasingly advocated [2].

In the past decade cancer imaging with FdG PET has become commonplace demonstrating that more than $90 \%$ of clinical cancers of sufficient size to be imaged take up glucose several fold more than adjacent normal tissue. Remarkably, although this appears to be the single most common property of the "tumor phenotype" the causes and consequences of glycolysis have rarely been considered as a therapeutic target. We propose that a new approach towards the war against cancer can be found in re-considering the critical differences in the metabolism of a tumor cell as compared to a normal one. More than 80 years ago the Nobel Prize winner Otto Heinrich Warburg discovered that tumors use glycolytic metabolism even in the presence of normal oxygen tension, an apparent paradox, since glycolysis is 18 -fold less efficient than oxidative phosphorylation in producing energy (ATP). He also found that cancer cells were, unlike normal cells, able to live in the acidic environment that developed as a consequence of elevated lactic acid production by glycolysis. Today, we know that the metabolic changes occurring during cancer progression are mediated by two major 
pathways, i.e. the activity of hypoxia-inducible factor 1 (HIF-1) and oncogene activation [3,4]. The selective ability of tumor cells to adapt their metabolism to a hostile microenvironment is revealing new therapeutic targets to selectively eliminate cancer cells $[5,6]$.

We propose that the development of new anti-cancer therapies should include a focus on understanding both abnormal glucose metabolism and mechanisms used by cancer cells to survive and proliferate in the hostile microenvironment. In the latter, a dominant role is played by protons accumulating at the tumor site as a result of highly proliferating cancer cells relying on glycolysis with high lactic acid production and limited removal due to poor perfusion. To avoid acidification of intracellular $\mathrm{pH}$, glycolytically-produced acid must be extruded by tumor cells through a number of proton transporters, such as V-ATPase [7], the $\mathrm{Na}^{+} / \mathrm{H}^{+}$exchanger (NHE) [8], the carbonic anhydrases [9], the proton linked monocarboxylate transporter MCTs [4], the $\mathrm{Cl}^{-} / \mathrm{HCO}^{-}$exchangers and ATP synthase [10]. The increased activity of these transporters cause reversal of the normal intra-extracellular $\mathrm{pH}$ gradients, so that cancer cells produce significant acidification of the extracellular microenvironment, while they maintain a normal or slightly alkaline $\mathrm{pH}$.

In contrast to cancer cells, the acidic extracellular space reduces viability and function of most normal cells including cytotoxic $\mathrm{T}$ cells that ordinarily mediate the immune response to tumor antigens. As a result, the tumor site becomes a relative sanctuary in which immune cells and other host cellular components are significantly inhibited. Interestingly, the acidic $\mathrm{pH}$ of tumor microenvironment also appears to favor the recruitment of immunosuppressive cells, such as myeloid-derived suppressor cells, further promoting escape from immune surveillance, neo-angiogenesis and stromal remodeling [11]. In addition, there is evidence that an acidic extracellular $\mathrm{pH}$ promotes invasiveness and metastatic behavior in several tumor models [12,13], through a number of mechanisms such as increased traffic of acidic vesicles [14] and increased release of exosomes [15], whose protumorigenic features are clearly emerging [16,17], lytic enzyme activation and matrix destruction $[12,18]$ as well as aberrant phagocytic activity [19].

Clearly, these complex interactions of tumor and microenvironment represent a dynamic non-linear system and, as a result, a number of multidisciplinary groups at the interface between scientific fields, i.e. physics, mathematics and biology, are attempting to provide a unified frame to address these changes theoretically and experimentally [20-22]. Understanding the interactions of the physical microenvironment and cellular properties will be required to exploit the tumor metabolism as a therapeutic strategy.
One emerging theme from this work is that the detoxification mechanisms that allow cancer cells to survive in extremely hostile conditions represent very appealing therapeutic targets. Thus, inhibition of membrane-bound carbonic anhydrases, proton pumps and transporters, which appear to be major pathways used by tumor cells to export protons [23-30], may represent a novel and promising target for exerting a pleiotropic, multifaceted suppression of cancer cell growth and progression. Several lines of evidence suggest that the majority of human cancers may potentially be responsive to therapies based on inhibition of mechanisms underlying tumor acidification [25-27].

Indeed, recent research has supported the idea that inhibiting tumor proton pumps and transporters may deprive cancer cells of a key mechanism of detoxification $[7,22,23]$. During the last decade, this $\mathrm{H}^{+}$related approach mainly focused on the dynamics of protons in cancer has integrated many basic and clinical aspects, as well as several areas of cancer research and treatment, under a unified perspective and paradigm in modern translational oncology [31]. However, to date proton pump inhibition as an antitumor strategy has remained neglected in the clinic, despite mounting evidence of its potential use as an inexpensive and relatively non-toxic treatment. For example, a class of proton pump inhibitors currently used to treat peptic ulcers has now entered clinical trials for treatment of patients affected by melanoma and osteosarcoma with the endpoints of evaluating the chemosensitization effect of pre-treatment with high dosages of esomeprazole.

Several research groups scattered all over the world have recently started to investigate various aspects of proton dynamics in cancer cells, with quite encouraging preliminary results. With the intent of unifying investigators involved in this line of research the First International Symposium entitled "Proton transport and its inhibition (PTI) in the etiopathogenesis, diagnosis and treatment of cancer" was held in Madrid, Spain, in April 2009. At this meeting we explored the main aspects of proton dynamics and the potential involvement in cancer etiology, etiopathogenesis and treatment. The main goals of this International Symposium were: a) To lead towards a unified and integrated understanding of the main role of $\mathrm{H}^{+}$dynamics in modern cancer research; b) To discuss the more recent scientific data of intra and extracellular $\mathrm{pH}$ abnormalities in the onset of cancer as well as in its local and metastatic progression, focusing mainly on the molecular mechanisms driving the alterations of $\mathrm{pH}$ in various tumor types and tissues; c) To shed light on new potential targets for inducing selective apoptosis and other therapeutic interventions in malignant tumors and leukemias resistant to traditional treatments. 
Both basic researchers and clinical oncologists participating at this meeting thought it was time to create a Society to attract the attention of lay people and the rest of the scientific community with respect to the emerging importance of acidity and proton dynamics in cancer pathogenesis and treatment. An intensive crosstalk between meeting attendees led to the formation of the "International Society for Proton Dynamics in Cancer" (ISPDC) in January 2010. This society is composed of researchers from all over the world who share the conviction that targeting tumor acidic $\mathrm{pH}$ could represent a significant advance in the treatment of most solid malignant tumors. Decreasing proton production, blocking proton extrusion, or increasing extracellular $\mathrm{pH}$ could result in a selective strategy to increase tumor cell death and/or to reduce proliferation and invasion.

The newly formed "International Society for Proton Dynamics in Cancer", focusing on the aspects of $\mathrm{pH}$ and/ or dynamics of protons in cancer, will meet again during its First International Meeting in Rome on September 27th-28th 2010 http://ispdc.net. Both basic researchers and clinical oncologists are called upon to participate in this meeting where we hope to create an ideal environment to discuss several aspects of these new therapeutic approaches and develop implementation plans. The aim of the meeting is to foster translational research and stimulate interdisciplinary collaboration for developing new treatment targets and more specific and less toxic therapeutic strategies based on the most recent knowledge on proton dynamics in tumor cell biology.

\section{Competing interests}

The authors declare that they have no competing interests.

\section{Authors' contributions}

All authors gave intellectual contributions and participated in writing the manuscript. All authors read and approved the final manuscript.

\section{Author Details}

${ }^{1}$ Unit of Immunotherapy of Human Tumors, Fondazione IRCCS Istituto Nazionale Tumori, Milan, Italy, ${ }^{2}$ Department of Therapeutic Research and Medicines Evaluation, Unit of Antitumor Drugs, Istituto Superiore di Sanità, Rome, Italy, ${ }^{3}$ nnstitute for Clinical Biology and Metabolism, Vitoria, Spain, 4Department of General and Environmental Physiology, University of Bari, Bari, Italy, 5 Department of Cell Biology, Johns Hopkins, Baltimore, MD, USA, 65 School of Veterinary Medicine \& Science, University of Nottingham, College Road, Sutton Bonington, LE12 5RD, UK, ${ }^{7}$ Institute of Developmental Biology \& Cancer, CNRS, Centre A. Lacassagne, University of Nice, France, ${ }^{8}$ Department of Radiology and Integrative Mathematical Oncology, Moffitt Cancer Center, Tampa, FL, USA and ${ }^{9}$ Cancer Center Karolinska, Karolinska Institute, Stockholm, Sweden

Received: 28 May 2010 Accepted: 15 June 2010

Published: 15 June 2010

\section{References}

1. Nygren P, Larsson R: Overview of the clinical efficacy of investigational anticancer drugs. J Intern Med 2003, 253:46-75.

2. Gatenby RA: A change of strategy in the war on cancer. Nature 2009 , 459:508-509.

3. Hsu PP, Sabatini DM: Cancer cell metabolism: Warburg and beyond. Cell 2008, 134:703-707.
4. Pouyssegur J, Dayan F, Mazure N: Hypoxia signaling in cancer and approaches to enforce tumor regression. Nature 2006, 441:437-443.

5. Jin S, DiPaola RS, Mathew R, White E: Metabolic catastrophe as a means to cancer cell death. J Cell Sci 2007, 120:379-383.

6. Tennant DA, Duran RV, Gottlieb E: Targeting metabolic transformation for cancer therapy. Nat Rev Cancer 2010, 10:267-277.

7. Fais S, De Milito A, You H, Qin W: Targeting vacuolar $\mathrm{H}^{+}$-ATPases as a new strategy against cancer. Cancer Res 2007, 67:10627-10630.

8. Cardone RA, Casavola V, Reshkin SJ: The role of disturbed pH dynamics and the $\mathrm{Na}^{+} / \mathrm{H}^{+}$exchanger in metastasis. Nat Rev Cancer 2005, 5:786-795

9. Supuran CT: Carbonic anhydrases: novel therapeutic applications for inhibitors and activators. Nat Rev Drug Discov 2008, 7:168-181.

10. Kenan DJ, Wahl ML: Ectopic localization of mitochondrial ATP synthase: a target for anti-angiogenesis intervention? J Bioenerg Biomembr 2005, 37:461-465

11. Gabrilovich DI, Nagaraj S: Myeloid-derived suppressor cells as regulators of the immune system. Nat Rev Immunol 2009, 9:162-174.

12. Martinez-Zaguilan R, Seftor EA, Seftor RE, Chu YW, Gillies RJ, Hendrix MJ: Acidic $\mathrm{pH}$ enhances the invasive behavior of human melanoma cells. Clin Exp Metastasis 1996, 14:176-186.

13. Gatenby RA, Gillies RJ: A microenvironmental model of carcinogenesis. Nat Rev Cancer 2008, 8:56-61.

14. Raghunand N, Martinez-Zaguilan R, Wright SH, Gillies RJ: $\mathrm{pH}$ and drug resistance. II. Turnover of acidic vesicles and resistance to weakly basic chemotherapeutic drugs. Biochem Pharmacol 1999, 57:1047-1058.

15. Parolini I, Federici C, Raggi C, Lugini L, Palleschi S, De Milito A, Coscia C lessi E, Logozzi M, Molinari A, Colone M, Tatti M, Sargiacomo M, Fais S: Microenvironmental $\mathrm{pH}$ is a key factor for exosome traffic in tumor cells. J Biol Chem 2009, 284:34211-34222.

16. Iero M, Valenti R, Huber V, Filipazzi P, Parmiani G, Fais S, Rivoltini L: Tumour-released exosomes and their implications in cancer immunity. Cell Death Differ 2008, 15:80-88.

17. Al-Nedawi K, Meehan B, Rak J: Microvesicles: messengers and mediators of tumor progression. Cell Cycle 2009, 8:2014-2018.

18. Lu X, Qin W, Li J, Tan N, Pan D, Zhang H, Xie L, Yao G, Shu H, Yao M, Wan D, Gu J, Yang S: The growth and metastasis of human hepatocellular carcinoma xenografts are inhibited by small interfering RNA targeting to the subunit ATP6L of proton pump. Cancer Res 2005, 65:6843-6849.

19. Lugini L, Matarrese P, Tinari A, Lozupone F, Federici C, lessi E, Gentile M, Luciani F, Parmiani G, Rivoltini L, Malorni W, Fais S: Cannibalism of live lymphocytes by human metastatic but not primary melanoma cells. Cancer Res 2006, 66:3629-3638.

20. Rauch C: Toward a mechanical control of drug delivery. On the relationship between Lipinski's 2 nd rule and cytosolic $\mathrm{pH}$ changes in doxorubicin resistance levels in cancer cells: a comparison to published data. Eur Biophys J 2009, 38:829-846.

21. Rauch C: On the relationship between drug's size, cell membrane mechanical properties and high levels of multi drug resistance: a comparison to published data. Eur Biophys J 2009, 38:537-546.

22. Rauch C, Pluen A: Multi drug resistance-dependent "vacuum cleaner" functionality potentially driven by the interactions between endocytosis, drug size and Pgp-like transporters surface density. Eur Biophys J 2007, 36:121-131.

23. Panagiotopoulou V, Richardson G, Jensen OE, Rauch C: On a biophysical and mathematical model of Pgp-mediated multidrug resistance: understanding the "space-time" dimension of MDR. Eur Biophys J 2010, 39:201-211

24. Lozupone F, Perdicchio M, Brambilla D, Borghi M, Meschini S, Barca S, Marino ML, Logozzi M, Federici C, lessi E, de Milito A, Fais S: The human homologue of Dictyostelium discoideum phg1 $\mathrm{A}$ is expressed by human metastatic melanoma cells. EMBO Rep 2009, 10:1348-1354

25. Wahl ML, Owen JA, Burd R, Herlands RA, Nogami SS, Rodeck U, Berd D, Leeper DB, Owen CS: Regulation of intracellular $\mathrm{pH}$ in human melanoma: potential therapeutic implications. Mol Cancer Ther 2002, 1:617-628.

26. Harguindey S, Arranz JL, Wahl ML, Orive G, Reshkin SJ: Proton transport inhibitors as potentially selective anticancer drugs. Anticancer Res 2009 , 29:2127-2136.

27. Chiche J, Ilc K, Laferriére J, Trottier E, Dayan F, Mazure NM, Brahimi-Horn MC, Pouysségur J: Hypoxia-inducible carbonic anhydrase IX and XII 
promote tumor cell growth by counteracting acidosis through the regulation of the intracellular pH. Cancer Res 2009, 69:358-368.

28. De Milito A, Canese R, Marino ML, Borghi M, lero M, Villa A, Venturi G, Lozupone F, lessi E, Logozzi M, Della Mina P, Santinami M, Rodolfo M, Podo F, Rivoltini L, Fais S: pH-dependent antitumor activity of proton pump inhibitors against human melanoma is mediated by inhibition of tumor acidity. Int J Cancer 2010, 127:207-219.

29. De Milito A, Fais S: Tumor Acidity, Chemoresistance and Proton Pump Inhibitors. Future Oncology 2005, 1:779-786.

30. Izumi H, Torigoe T, Ishiguchi H, Uramoto H, Yoshida Y, Tanabe M, Ise T, Murakami T, Yoshida T, Nomoto M, Kohno K: Cellular pH regulators: potentially promising molecular targets for cancer chemotherapy. Cancer Treat Rev 2003, 29:541-549.

31. Harguindey S, Orive G, Luis Pedraz J, Paradiso A, Reshkin SJ: The role of pH dynamics and the $\mathrm{Na}^{+} / \mathrm{H}^{+}$antiporter in the etiopathogenesis and treatment of cancer. Two faces of the same coin-one single nature. Bioch Biopyhs Acta 2005, 1756:1-24

doi: $10.1186 / 1479-5876-8-57$

Cite this article as: Huber et al., Proton dynamics in cancer Journal of Translational Medicine 2010, 8:57

Submit your next manuscript to BioMed Central and take full advantage of:

- Convenient online submission

- Thorough peer review

- No space constraints or color figure charges

- Immediate publication on acceptance

- Inclusion in PubMed, CAS, Scopus and Google Scholar

- Research which is freely available for redistribution

Submit your manuscript at www.biomedcentral.com/submit
C Biomed Central 